\title{
DEVELOPMENT OF TIME VARYING SLIDING MODE CONTROLLER WITH FUZZY SYSTEM FOR AUTOMATIC EXCAVATOR
}

\author{
Jeongju Choi* \\ Technical Center of High Performance Valves, Dong-A University, Busan, Korea \\ * Corresponding author(Jchoi72@dau.ac.kr)
}

\begin{abstract}
Time-varying sliding mode controller(TVSMC) with fuzzy algorithm for an unmanned automatic excavator system is proposed in this paper. Proposed control system is induced from dynamics of 3-link excavator that is boom, arm and bucket. To design the proposed control system, the main structure of controller is based on sliding mode controller(SMC) with time varying sliding surface. In case of TVSMC the robustness of closed loop system can be guaranteed with small chattering but the tracking performance depends on the behavior of sliding surface. Therefore, TVSMC with fuzzy algorithm is proposed in this paper. In the proposed control system, fuzzy algorithm is designed to decide the slop of time varying sliding surface based on the tracking response. As the slop of sliding surface is changed based on the tracking response, a better transient response can be obtained. The proposed control law is applied to the tracking control system of the developed automatic excavator system and the performance is evaluated through experiments.
\end{abstract}

Keywords: Automatic Excavator, Sliding Mode Controller, Fuzzy

\section{INTRODUCTION}

Excavator is the equipment that can perform the various works with replaceable device at end-effect. However, due to the simple and repeated work, the fatigue of operator is accumulated and this can causes the safety accidents. This kind of monotones and repeated work can be covered by the automation of the excavator and it can perform the work more effectively, also the safety of operator can be secured in dangerous work environment. Therefore, the demand for automatic excavator systems has steadily increased leading to active research in this area. The main issue with an automatic excavator is to build a proper closed-loop control system for each link of the excavator which is driven by a hydraulic system. The representative control system for an automatic excavator system have been applied to an impedance control, PID controller and time delay control[1][2][3]. Also, an optimal control system were investigated to improve the performance the power system in a hybrid hydraulic excavator by [4][5][6]. For the robust tracking control of the hydraulic system in the excavator, control of the hydraulic single-rod cylinder using an electro hydraulic manipulator was studied[7].
However, the implementation of such systems tends to demand a large number of computations whereas a mathematical proof of their stability cannot be obtained with ease.

This paper represents the development of an automatic excavator system with modifying the MCV(Main Control Valve) and proposes the robust control system to control the hydraulic actuator. For the robust control system, the TVSMC with fuzzy algorithm is proposed. In order to construct the automatic excavator system, EPPR(Electronic Proportional Pressure Reducing) valve installed on the $\mathrm{MCV}$ to control the pilot pressure of MCV. Based on the developed automatic excavator system, robust tracking control system is designed using TVSMC with fuzzy algorithm. the proposed tracking control system is design to improve the performance of conventional SMC. In general, conventional SMC can guarantee the robustness for the uncertainty of the system and disturbance but the high frequency chattering is generated by switching term and this may cause the damage on the hardware[8]. In order to reduce chattering phenomenon of conventional SMC, the proposed controller is designed the sliding 
surface can be changed depend on the tracking response based on reaching law method. Since the proposed TVSMC with fuzzy algorithm can the state variables can sustain on the designed sliding surface from initial state, the transient response can be improved.

The rest of the paper is organized as follows. The construction of the auto excavator system is described briefly on section 2, and TVSMC design procedure and the application of the fuzzy algorithm is described on section 3 . Also, the response performance that was described in section 4. The conclusion remarks in section 5 .

\section{AUTOMATIC EXCAVATOR SYSTEM}

1.5 ton excavator of D company shown in Fig. 1 was used for this research. The specification of the excavator is represented in Table 1. To construct an automatic excavator, EPPR valves mounted on the MCV of excavator.

The function of EPPR valve was to control the pilot pressure of MCV. The control of EPPR valve was configured to operate by PC and electric joystick. Control input of PC is for automatic operation and electric joystick is for by an operator. In order to detect the position of each link of excavator, a resolver was installed on the linkage area. The measured angle of each link through resolver is transmitted to the PC using RS-232. The pressure of the hydraulic cylinder mounted on each link was also measured by the pressure sensors. The installed resolver and EPPR valve of the developed excavator system are shown in Fig. 2. The DAQ (Data Acquisition) of the auto excavator system was set up by PXI type N. I. (National Instrument corp.) board.

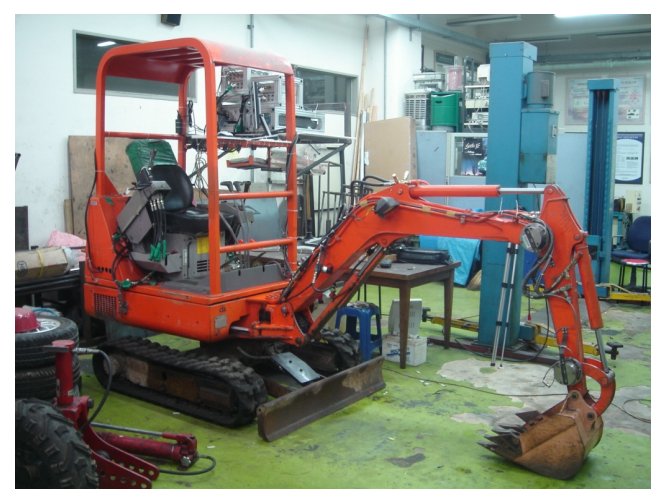

Fig. 1 1.5ton excavator system
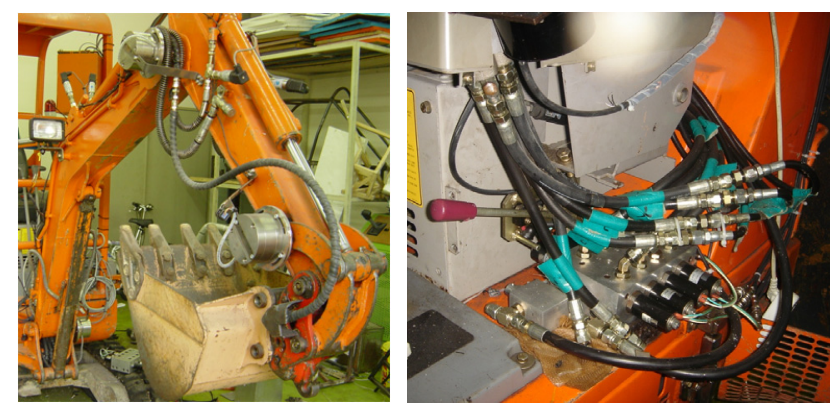

Fig. 2 Installed resolver and EPPR valve

Table 1 Specification of the used excavator

\begin{tabular}{|c|c|c|}
\hline Part & \multicolumn{2}{|c|}{ Specification } \\
\hline \multirow{5}{*}{ Main pump } & Type & Tandem, axial piston \\
\hline & Quantity & 1 \\
\hline & Displacement & $2 \times 6.1 \mathrm{cc} / \mathrm{rev}$ \\
\hline & Max. flow rate & $2 \times 14.6 \mathrm{l} / \mathrm{min}$ \\
\hline & Weight & $19.5 \mathrm{Kg}$ \\
\hline \multirow{4}{*}{$\begin{array}{c}\text { Pump(S/W, } \\
\text { Boom S/W, } \\
\text { D/Z) }\end{array}$} & Type & Gear \\
\hline & Displacement & $4.5 \mathrm{cc} / \mathrm{rev}$ \\
\hline & Max. flow rate & $10.8 \mathrm{l} / \mathrm{min}$ \\
\hline & Relief valve & $165 \mathrm{Kg} / \mathrm{Cm}^{2}$ \\
\hline \multirow{4}{*}{ Pilot pump } & Type & Gear \\
\hline & Displacement & $6.5 \mathrm{cc} / \mathrm{rev}$ \\
\hline & Max. flow rate & $15.6 \mathrm{l} / \mathrm{min}$ \\
\hline & Relief valve & $25 \mathrm{Kg} / \mathrm{Cm}^{2}$ \\
\hline \multirow{6}{*}{ Control valve } & Type & Pilot \& manual control \\
\hline & No. of spools & 9 \\
\hline & Spool dia. & 12 \\
\hline & $\begin{array}{c}\text { Spool } \\
\text { arrangements }\end{array}$ & $\begin{array}{c}\text { BKT, BM1, TR DZ, } \\
\text { B/SW,S/W, ARM, TL, } \\
\text { BM2 } \\
210 / 165 \mathrm{Kg} / \mathrm{Cm}^{2}\end{array}$ \\
\hline & $\begin{array}{l}\text { Port relief valve } \\
\text { pressure }\end{array}$ & $250 \mathrm{Kg} / \mathrm{Cm}^{2}$ AT $5 l / m i n$ \\
\hline & Weight & $24 \mathrm{Kg}$ \\
\hline
\end{tabular}

3. ASLIDING MODE CONTROLLER WITH TIME VARYING SLIDING SURFACE USING FUZZY LOGIC

\subsection{PROPOSED SLIDING SURFACE}

Since conventional sliding mode control system generally cause the hardware damage due to the high frequency chattering, the sliding mode control system based on the 
reaching law has been suggested. The sliding mode control system designed based on the reaching law becomes the form of the continuous structure that is proportional factor for the sliding variables. Even though this structure of sliding mode controller can reduce the high frequency chattering, the steady state response is to be poor. Therefore, TVSMC is proposed in this paper. The proposed TVSMC can make the state variables stay on the sliding surface from initial state. In order to design the time varying sliding surface, the estimated error were selected as follows:

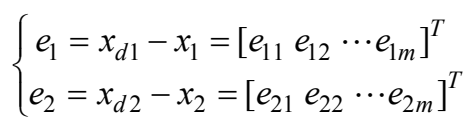

where $x_{d 1}$ and $x_{d 2}$ are the desired system states.

The proposed time varying sliding surface is selected

$s\left(x_{1}, x_{2}, t\right)=e_{2}+\Lambda\left(e_{1}, e_{2}\right) e_{1}+\mu(t)$

where

$$
\begin{aligned}
& \Lambda(t)=\operatorname{diag}\left[\lambda_{1}(t) \lambda_{2}(t) \cdots \lambda_{m}(t)\right], \\
& \lambda_{i}(t)=\left\{\begin{array}{cc}
\lambda_{0 i}+\lambda_{g i} t, & 0 \leq t<t_{f i} \\
\lambda_{f i}, & t \geq t_{f i}
\end{array} \quad(i=1,2, \cdots, m)\right.
\end{aligned}
$$

and the translational distance $\mu(t)$ is expressed as

$$
\mu(t)=\left[\mu_{1}(t) \mu_{2}(t) \cdots \mu_{m}(t)\right]^{T}
$$

When the initial state of the error $\left(e_{1 i}(0), e_{2 i}(0)\right)$ is located in the 1st or the 3rd quadrant in the phase plane, the combinational type is used, and the parameters of the timevarying sliding surface are obtained as

$$
\begin{gathered}
\lambda_{0 i}=0, \quad \lambda_{g i}=\lambda_{f i} / t_{f i} \\
\mu_{0 i}=-e_{2 i}(0), \quad \mu_{g i}=e_{2 i}(0) / t_{f i}
\end{gathered}
$$

When the initial state of the error is located in the $2 \mathrm{nd}$ or the 4th quadrant in the phase plane the rotational type is used, and the parameters of the time-varying sliding surface are obtained as

$$
\begin{array}{cc}
\lambda_{0 i}=-e_{2 i}(0) / e_{1 i}(0), & \lambda_{g i}=\left(\lambda_{f i}-\lambda_{0 i}\right) / t_{f i} \\
\mu_{0 i}=0, & \mu_{g i}=0
\end{array}
$$

And the final sliding surface is written as

$s\left(x_{1}, x_{2}, t\right)=e_{2}+\Lambda_{f} e_{1}$

where the slope of the final sliding surface is expressed as $\Lambda_{f}=\operatorname{diag}\left[\begin{array}{llll}\lambda_{f 1} & \lambda_{f 2} & \cdots & \lambda_{f i}\end{array}\right]$.

The designed sliding surface is function of $\Lambda_{f}$ and that affects to the transient response. In order to decide the slope of sliding surface, the fuzzy algorithm is used in this paper. To design a fuzzy logic, error and derivative of error is selected in term of input variable and output of fuzzy system. The designed input and output membership functions are represented in Fig. 3.

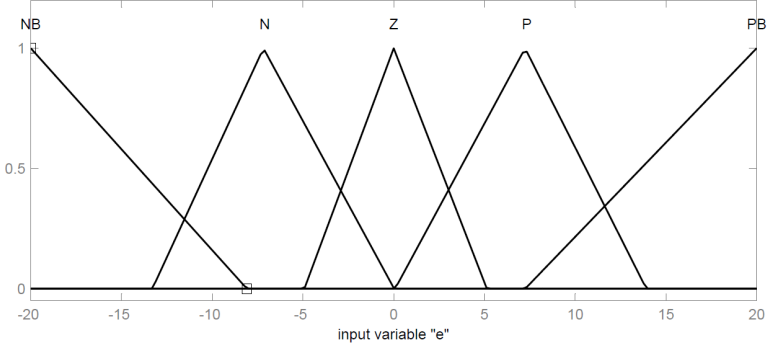

a) Input membership function for error

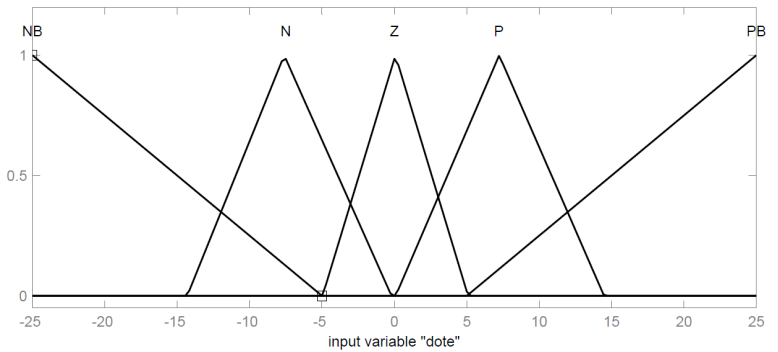

b) Input membership function for the derivative of error

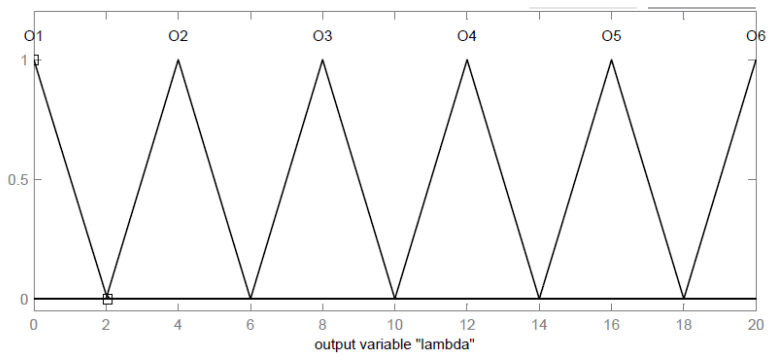

c) Output membership function for lambda

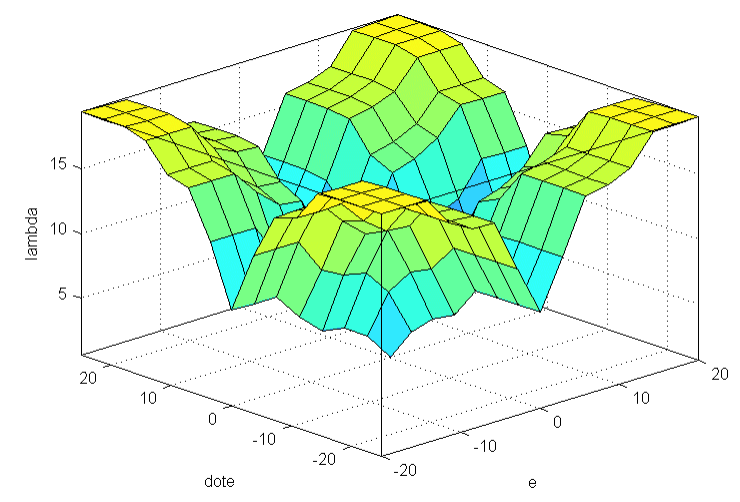

d) Surface of fuzzy rules

Fig. 3 Fuzzy rule for the sliding surface 
Table 2 Designed fuzzy rule

\begin{tabular}{|c|c|c|c|c|c|c|}
\hline \multicolumn{2}{|c|}{} & \multicolumn{5}{|c|}{ Derivative of error } \\
\cline { 3 - 7 } & NB & N & Z & P & PB \\
\hline \multirow{7}{*}{ error } & NB & O6 & O5 & O3 & O5 & O6 \\
\cline { 2 - 7 } & N & O5 & O4 & O2 & O4 & O5 \\
\cline { 2 - 7 } & Z & O3 & O2 & O1 & O2 & O3 \\
\cline { 2 - 7 } & P & O5 & O4 & O2 & O4 & O5 \\
\cline { 2 - 7 } & PB & O6 & O5 & O3 & O5 & O6 \\
\hline
\end{tabular}

Based on the membership function, the fuzzy rules are designed as shown in Table 2. The defuzzification method is used by mandani method. d) of Fig. 3 shows the surface of fuzzy rules.

\subsection{DESIGN A SLIDING MODE CONTROL SYSTEM}

To design the sliding mode control law, the following regular form for dynamic systems is considered[4].

$\left\{\begin{array}{l}\dot{x}_{1}=f_{1}\left(x_{1}, x_{2}\right) \\ \dot{x}_{2}=f_{2}\left(x_{1}, x_{2}\right)+B_{2}\left(x_{1}, x_{2}\right) u+B_{2}\left(x_{1}, x_{2}\right)\end{array}\right.$

where $f_{1}\left(x_{1}, x_{2}\right)$ and $f_{2}\left(x_{1}, x_{2}\right)$ are system dynamics, $x_{1} \in R^{n-m}$ and $x_{2} \in R^{m}$ are state vectors, $u \in R^{m}$ is the control input, and $B_{2}$ is the input matrix which satisfies $\operatorname{rank}\left(B_{2}\right)=m$. And $d$ is the disturbance that is assumed to satisfy the matching condition and that includes modeling uncertainties, parameter variations and external loads. A sliding surface $S$ is defined as follows:

$S=\left\{x: s\left(x_{1}, x_{2}, t\right)=0\right\}$

where the sliding function $s\left(x_{1}, x_{2}, t\right)$ is continuous.

Using the reaching law method $[5,6]$, the dynamics of the sliding function $s$ is determined through the following differential equation

$\dot{s}=-D s-k \operatorname{sgn}(s)$

where the control gain of the continuous proportional term $D$ is a positive definite diagonal matrix and the control gain of the discontinuous switching term $k$ is also a positive definite diagonal matrix. From the derivative of the sliding function $s\left(x_{1}, x_{2}, t\right)$, Eq. (10) is expanded as

$\frac{\partial s}{\partial t}+\frac{\partial s}{\partial x_{1}} \dot{x}_{1}+\frac{\partial s}{\partial x_{2}} \dot{x}_{2}=-D s-k \operatorname{sgn}(s)$
To the system Eq. (8), the control input satisfies Eq. (11) can be obtained as

$u=u_{e q}-\left(\frac{\partial s}{\partial x_{2}} B_{2}\right)^{-1} D s-\left(\frac{\partial s}{\partial x_{2}} B_{2}\right)^{-1} k \operatorname{sgn}(s)$

where the equivalent control input $u_{e q}$ is expressed as

$u_{e q}=-\left(\frac{\partial s}{\partial x_{2}} B_{2}\right)^{-1}\left\{\frac{\partial s}{\partial t}+\frac{\partial s}{\partial x_{1}} f_{1}+\frac{\partial s}{\partial x_{2}} f_{2}\right\}-d$

The equivalent control input Eq. (6) has an unknown term $d$. Thus, it is hard to be applied in this form. The equivalent control input is separated into two parts, the disturbance and the others.

$u_{e q}=u_{e q}^{n}-d$

where the nominal equivalent control input $u_{e q}^{n}$ is expressed as

$u_{e q}^{n}=-\left(\frac{\partial s}{\partial x_{2}} B_{2}\right)^{-1}\left\{\frac{\partial s}{\partial t}+\frac{\partial s}{\partial x_{1}} f_{1}+\frac{\partial s}{\partial x_{2}} f_{2}\right\}$

If the upper boundary of disturbance $d$ is known, the nominal equivalent control input $u_{e q}^{n}$ can substitute for the equivalent control input $u_{e q}$ in Eq. (12). The modified control input can be written as

$u=u_{e q}^{n}-\left(\frac{\partial s}{\partial x_{2}} B_{2}\right)^{-1} D s+K \operatorname{sgn}(s)$

where $K$ is expressed as

$K=-\left(\frac{\partial s}{\partial x_{2}} B_{2}\right)^{-1} k$

In order to apply the proposed control system, The kinetic coordinate and the dynamics of the automatic excavator selected as shown in Fig. 4 and Eq. (17).

$J(\theta) \ddot{\theta}+h(\theta, \dot{\theta})+g(\theta)=\tau$

where

$J(\theta)=\left[\begin{array}{lll}J_{11} & J_{12} & J_{13} \\ J_{21} & J_{22} & J_{23} \\ J_{31} & J_{32} & J_{33}\end{array}\right]$, and elements of $J(\theta)$ are that

$J_{11}=a_{1}+2 c_{1}+2 c_{2}+2 c_{3}+2 c_{4}$,

$J_{12}=J_{21}=a_{2}+c_{1}+c_{2}+c_{3}+2 c_{4}$,

$J_{13}=J_{31}=a_{3}+c_{3}+c_{4}$,

$J_{22}=a_{2}+2 c_{4}, J_{23}=J_{32}=a_{3}+c_{4}, J_{33}=a_{3}$

$a_{1}=a_{2}+m_{1} l_{1}^{2}+m_{2} L_{1}^{2}+m_{3} L_{1}^{2}+I_{1}$,

$a_{2}=a_{3}+m_{2} l_{2}^{2}+m_{3} L_{2}^{2}+I_{2}, \quad a_{3}=m_{3} l_{3}^{2}+I_{3}$,

$c_{1}=m_{2} L_{1} l_{2} \cos \left(\theta_{2}\right), \quad c_{2}=m_{3} L_{1} L_{2} \cos \theta_{2}$, 
$c_{3}=m_{3} L_{1} l_{3} \cos \left(\theta_{2}+\theta_{3}\right), \quad c_{4}=m_{3} L-2 l_{3} \cos \left(\theta_{3}\right)$.

Each factor of $h(\theta, \dot{\theta})=\left[h_{1} h_{2} h_{3}\right]^{T}$ for the Coriolis force and centrifugal force and $g(\theta)=\left[\begin{array}{lll}g_{1} & g_{2} & g_{3}\end{array}\right]^{T}$ for the gravity would be as follows:

$$
\begin{aligned}
h_{1}= & -\left(s_{1}+s_{2}+s_{3}\right)\left(2 \dot{\theta}_{1}+\dot{\theta}_{2}\right) \dot{\theta}_{2}-\left(s_{3}+s_{4}\right)\left(2 \dot{\theta}_{1}+2 \dot{\theta}_{2}+\dot{\theta}_{3}\right) \dot{\theta}_{3} \\
h_{2}= & \left(s_{1}+s_{2}+s_{3}\right) \dot{\theta}_{1}^{2}-s_{4}\left(2 \dot{\theta}_{1}+2 \dot{\theta}_{2}+\dot{\theta}_{3}\right) \dot{\theta}_{3}, \\
h_{3}= & \left(s_{3}+s_{4}\right) \dot{\theta}_{1}^{2}+s_{4}\left(2 \dot{\theta}_{1}+\dot{\theta}_{2}\right) \dot{\theta}_{2}, \\
g_{1}= & -m_{1} l_{1} g \sin \left(\theta_{1}\right)-\left(m_{2}+m_{3}\right) L_{1} g \sin \theta_{1} \\
& -m_{2} l_{2} g \sin \left(\theta_{1}+\theta_{2}\right)-m_{3} L_{2} g \sin \left(\theta_{1}+\theta_{2}\right) \\
& -m_{3} l_{3} g \sin \left(\theta_{1}+\theta_{2}+\theta_{3}\right) \\
g_{2}= & -m_{2} l_{2} g \sin \left(\theta_{1}+\theta_{2}\right)-m_{3} L_{2} g \sin \left(\theta_{1}+\theta_{2}\right) \\
& -m_{3} l_{3} g \sin \left(\theta_{1}+\theta_{2}+\theta_{3}\right) \\
g_{3}= & -m_{3} l_{3} g \sin \left(\theta_{1}+\theta_{2}+\theta_{3}\right) \\
s_{1}= & m_{2} L_{1} l_{2} \sin \left(\theta_{2}\right), s_{2}=m_{3} L_{1} L_{2} \sin \theta_{2}, \\
s_{3}= & m_{3} L_{1} l_{3} \sin \left(\theta_{1}+\theta_{2}\right), s_{4}=m_{3} L_{2} l_{3} \sin \left(\theta_{3}\right) .
\end{aligned}
$$

The continuous structure sliding mode controller is designed based on Eqs. (16) and (17) as follows:

$u=u_{e q}^{n}+J(\theta) h(\theta, \dot{\theta}) s+\operatorname{Ksat}(s)$

where $u_{e q}^{n}=J^{-1}\left[\ddot{x}_{d}+\Lambda \dot{e}+\dot{\Lambda} e+\dot{\mu}\right]+h(\theta, \dot{\theta})$.

\section{EXPERIMENTS}

The reference signal was generated so that the displacement at the end-effect of the automatic excavator can be moved on diagonal direction to verify the command following performance of the proposed control system. The gain of the controller was tuned by means of the trial and error. Figs. 5 to 7 is the response result of the boom, arm and bucket. The behavior of the end-effect is shown in Fig. 8 .

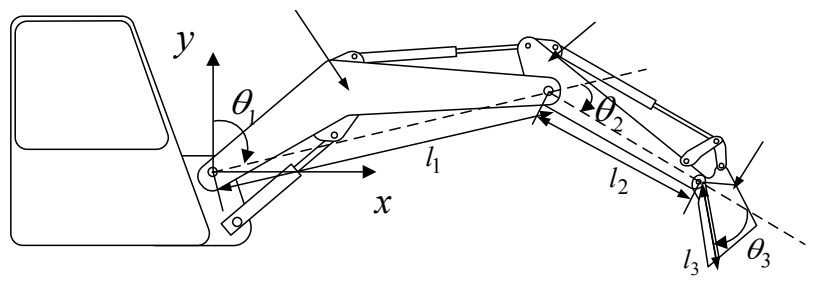

Fig. 4 Kinetic coordinate of the excavator system

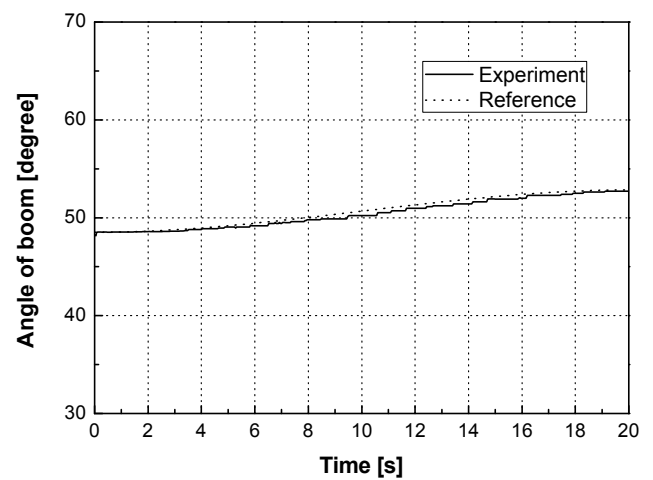

Fig. 5 Experimental result for the boom link

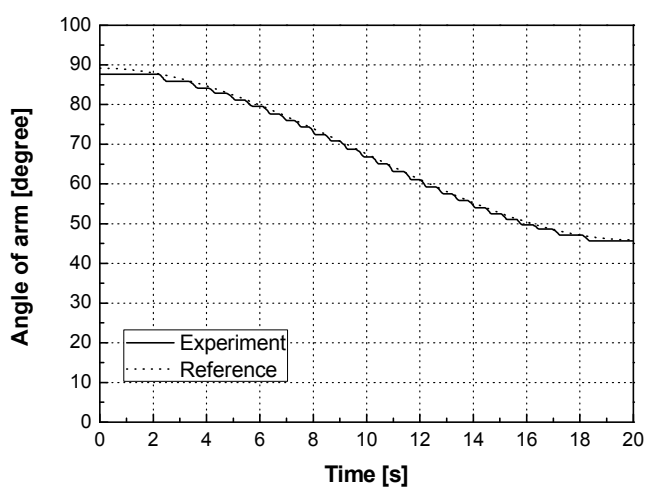

Fig. 6 Experimental result for the arm link

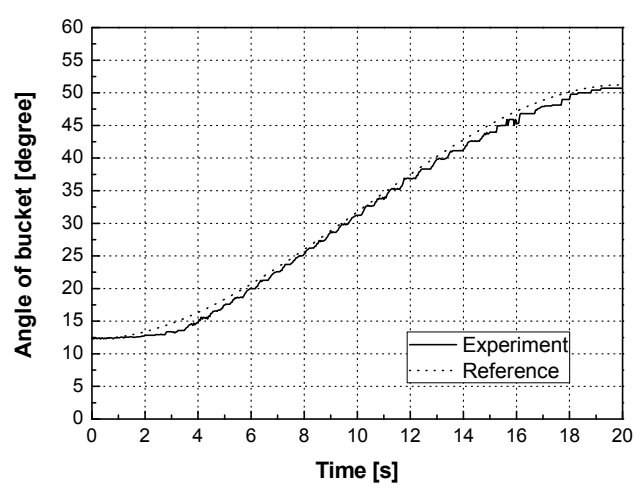

Fig. 7 Experimental result for bucket link

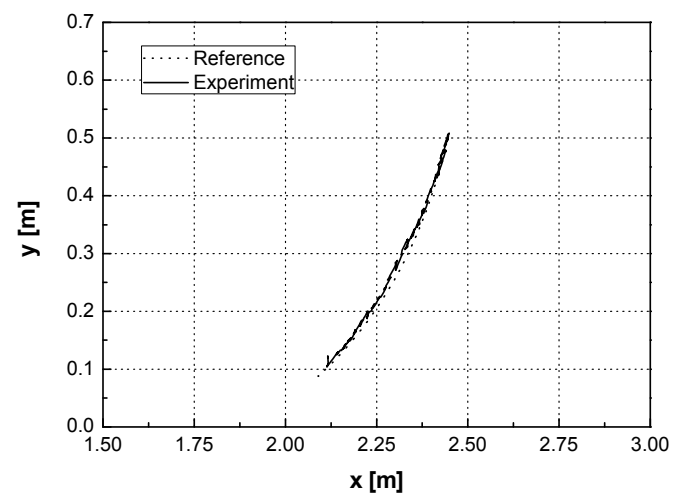

Fig. 8 Tracking result for end-effect 
In order to evaluate the performance of the proposed control system, the regulation performance of the arm was analyzed by applying to the step input at the boom. When the step input was excited to the boom link, the control law of arm link was set to keep the initial position. The response of arm link was compared TVSMC and TVSMC with Fuzzy algorithm was compared because the step response of boom affects to the arm link as disturbance. During this comparison $t_{f i}$ for the TVSMC was selected as 2 and the rest of the SMC parameters were remained the same with both controller. Fig. 9 represents the response result of the arm link. As shown in result, It is found that the response of the proposed control law is faster than TVSMC law and the performance of disturbance cancellation is superior to TVSMC.

\section{CONCLUSION}

In this research, the existing 1.5 ton excavator was used to construct the automatic excavator system. The angle of each link of the excavator was detected by resolvers, and EPPR valve was installed on MCV to control the pilot pressure of MCV. To design the control law of each link, TVSMC with Fuzzy algorithm was used. The proposed control system designed the state variable stay on the designed sliding surface from the initial position. Also, the time varying sliding surface was designed to be changed properly depending on the response characteristics by applying the fuzzy algorithm. The performance of the suggested control system was verified by the experiment.

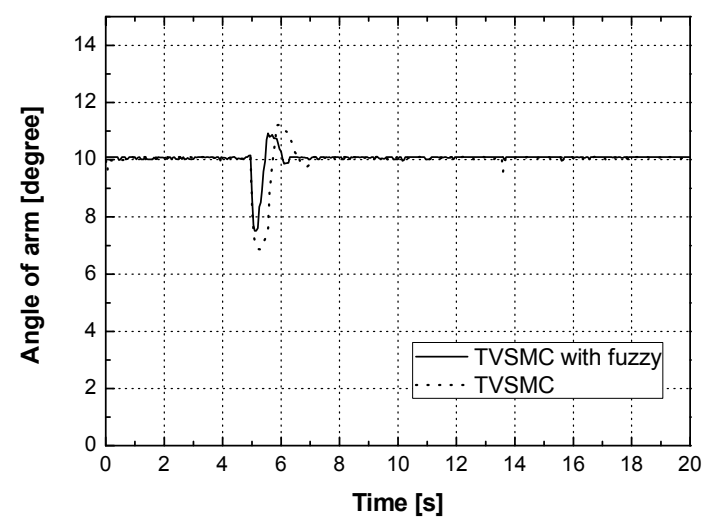

Fig. 9 Angle of arm for the step response of boom

\section{ACKNOWLEDGEMENT}

This work was supported by Technical Center for High Performance Valves Form the Regional Innovation Center(RIC)Program of the Ministry of Knowledge Economy(MKE),Korea.

\section{REFERENCES}

[1] Tafazoli, S., Salcudean, E. S., Keyvan, H. Z. and Lawrence, P. D., "Impedance Control of a Teleoperated Excavator," IEEE Transactions on Control Systems Technology, Vol. 10(3), pp. 355-367, 2002.

[2] Gu, J., Taylor, J. and Seward, D., "ProportionalIntegral-Plus Control of an Intelligent Excavator," Computer-Aided Civil and Infrastructure Engineering, Vol. 19, pp. 16-27, 2004.

[3] Song, B. and Koivo, A. J., "Neural Adaptive Control of Excavators," International Conference on Intelligent Robots and Systems, Vol. 1, pp. 162-167, 1995.

[4] Xiao, Q., Wang, Q. and Zhang, Y., "Control Strategies of Power System in Hybrid Hydraulic excavator," Automation in Construction, Vol. 16(5), pp. 1-7. 2007.

[5] Gross, D. C. and Rattan, K. S., "A feedforward MNN controller for pneumatic cylinder trajectory tracking control," International Conference on Neural Networks, Vol. 2(9), June, pp. 794-799, 1997.

[6] Lim, O. K. and Cho, H., "Optimal Shape Design of Excavator Boom Using the Semi-Analytical Method," Journal of KSME(domestic), Vol. 19(1), pp. 301-309, 1995. [7] Tafazoli, S., Clarence, W. S. and Peter D. L., "Tracking Control of an Electro-hydraulic Manipulator in the Presence of Friction," IEEE Transactions on Control Systems Technology, Vol. 6(3), pp. 401-411, 1998.

[8] Zhang, D. Q. and S. K. Panda, "Chattering-free and fast-response sliding mode controller," Proceedings of IEE Control Theory and Application. Vol. 146(2), pp. 171-177. 1999. 